\title{
Effects of Constrictor Geometry, Arc Current, and Gas Flow Rate on Thermal Plasma Characteristics in a Segmented Arc Heater*
}

\author{
Sooseok CHOI**, Jin Myung PARK ${ }^{* * *}$, Won Tae JU**** \\ and Sang Hee HONG***** \\ ** Center for Advance Research in Fusion Reactor Engineering, Seoul National University \\ 599 Gwanak-ro, Gwanak-gu, Seoul 151-742, Republic of Korea \\ E-mail:sooseok.choi@gmail.com \\ *** Oak Ridge National Laboratory \\ P.O. Box 2008, Oak Ridge TN 37831, USA \\ **** Plasnix Co., Ltd. \\ 630-7 Namchon-dong, Namdong-gu, Incheon 405-100, Republic of Korea \\ ***** Department of Nuclear Engineering, Seoul National University \\ 599 Gwanak-ro, Gwanak-gu, Seoul 151-742, Republic of Korea
}

\begin{abstract}
A numerical simulation on a segmented arc heater which is used to generate high thermal flow environments for the test of heat shield materials, were carried out. In this numerical prediction work, targets level of input power class, minimum enthalpy at the exit of the heater, and maximum pressure inside the heater were set up as $400 \mathrm{~kW}, 20 \mathrm{MJ} / \mathrm{kg}$, and $4 \mathrm{bar}$, respectively. In order to produce uniform temperature and velocity characteristics of thermal flow for a successful test, effects of design and operation variables on the thermal plasma characteristics were analyzed. Number of the segments packs and diameter of the constrictor were changed $1 \sim 3(105 \sim 315 \mathrm{~mm})$ and $12 \sim 20 \mathrm{~mm}$, respectively. As the torch operating variables, arc current was changed from $300 \mathrm{~A}$ to $500 \mathrm{~A}$ and plasma forming gas flow rate was varied from $6 \mathrm{~g} / \mathrm{s}$ to $14 \mathrm{~g} / \mathrm{s}$. Arc current was adjusted to achieve about $400 \mathrm{~kW}$ according to constrictor geometry at fixed gas flow rate of $10 \mathrm{~g} / \mathrm{s}$, and optimal design conditions for uniform radial temperature and low pressure profiles with Mach number 1 at the supersonic throat were expected when the constrictor length and diameter were $315 \mathrm{~mm}$ and $16 \mathrm{~mm}$, respectively. From the numerical results, diameters of the supersonic nozzle exit which determines test target size were calculated as $55.5 \mathrm{~mm}$ and $82.4 \mathrm{~mm}$ in the cases of Mach number 2 and 3 , respectively.
\end{abstract}

Key words: Thermal Plasma, Segmented Arc Heater, Thermal Protection System, Design and Operation Variables, Numerical Simulation

\section{Introduction}

Thermal plasma troches have been used to test heat protection materials or components those are used in the extremely high thermal flow environment like as the reentry vehicle ${ }^{(1-3)}$. Among various plasma torches, the segmented arc heater with a high input power of several tens MW operates in a relatively stable arc discharge with an excellent repeatability, though it is a complex unit with many components and critical alignment ${ }^{(1)}$. In the present work, an

${ }^{*}$ Received 1 Feb., 2011 (No. 11-0090) [DOI: 10.1299/jtst.6.210]

Copyright $\mathbb{C} 2011$ by JSME 
arc heater with a relatively low input power about $400 \mathrm{~kW}$ was numerically analyzed for the purposed of a basic design study of the segmented arc heater.

Generally, a large volume, sufficiently high enthalpy and Mach number at the exit of the arc heater with a stable operation are required in the test of thermal protection system (TPS) components. In order to generate those characteristics with the segmented arc heater, numerical simulations on the thermal plasma properties inside the arc heater are required under various conditions. Because the thermal flow properties inside the plasma torch are strongly affected by design and operation variables. Therefore, fitted conditions for the segmented arc heater with $400 \mathrm{~kW}$ level were analyzed in the present numerical work.

\section{Nomenclature}

$A$ : cross-sectional area at the supersonic nozzle exit

$A^{*}$ : cross-sectional area at the supersonic nozzle throat

A : magnetic vector potential

B : magnetic field

$D$ : diameter of constrictor

$d$ : diameter of supersonic throat

$G$ : air flow rate for plasma forming gas

$I$ : arc current

j : arc current density

$k$ : turbulent kinetic energy

$L$ : length of constrictor

$M$ : Mach number

$\mathbf{v}:$ plasma velocity

$\gamma:$ isentropic exponent

$\varepsilon:$ turbulent dissipation rate

$\mu_{0}$ : magnetic permeability of free space

$\phi$ : electric potential

$\sigma:$ electric conductivity

\section{Numerical Simulation Method}

The arc discharge and the thermal plasma jet generated in the segmented arc heater was simulated by using a magnetohydrodynamic (MHD) code, DCPTUN, which has been developed in the author's laboratory ${ }^{(4-9)}$. For the numerical simulation, the governing fluid equations consisting of mass, momentum and energy conservation, were solved under the steady-state, two-dimensional, and axis-symmetric conditions. Although the arc discharge is an inherently three-dimensional time transient phenomena, an axis-symmetric steady-state modeling on thermal plasma jet have been in good agreement with experimentally measured results $^{(7-9)}$. Because both the constricted arc column and the enhanced mixing effects of the turbulent flow are responsible for the gradual relaxation of the time transient three-dimensional structures of plasma fields into the steady-state two-dimensional axis-symmetric fields ${ }^{(9)}$. Furthermore, both arc spots on anode and cathode surfaces are almost fixed in axial direction due to segments structure, and they rotate azimuthally because of the magnetic body force induced by the arc discharge. In order to include radiation effects, optically thin plasma with the net emission coefficient in a local thermodynamic equilibrium (LTE) state was assumed ${ }^{(10)}$. Since the $k$ - $\varepsilon$ turbulence model has been widely used for a numerical modeling for the high velocity arc plasma jet, it was also incorporated to include turbulence effects inside the arc heater ${ }^{(4-11)}$.

Electromagnetic properties such as current density and magnetic field are important to 
simulate thermal plasma characteristics, because heat and momentum transfers from the constricted arc column to the plasma forming gas are largely affected by Joule heating and Lorentz force. Therefore, distribution of the arc current density, $\mathbf{j}$ was obtained from the current continuity equation, along with the generalized Ohm's law. The combination of these two equations results in an equation for the electric potential, $\phi$, as follow:

$$
\nabla \cdot(\sigma \nabla \phi)=\nabla \cdot(\sigma \mathbf{v} \times \mathbf{B})
$$

where, $\sigma$ is electric conductivity and $\mathbf{v}$ is plasma velocity calculated in the code, respectively. Including the electric conductivity, thermodynamic and transport properties such as density, specific enthalpy, viscosity, thermal conductivity, and net emission coefficient of air which was supplied as the plasma forming gas were used from the high temperature thermal plasma date in Ref. (12). In the segmented arc heater, external axial magnetic fields are commonly applied on the electrodes region to reduce their erosions by dispersing an enormous heat load of the arc spot azimuthally. However, the arc rotation driven by the external magnetic field was not accounted for the simplicity of the calculation, because the axis-symmetric condition which reflects uniform azimuthal distributions of the arc and heat load was assumed in the modeling. On the other hands, the self-induced magnetic field, $\mathbf{B}$ developed by the arc current was considered to include axial and radial momentum transfers caused by Lorentz force. The magnetic field, $\mathbf{B}$ can be found from the equation of $\mathbf{B}=\nabla \times \mathbf{A}$ by using the magnetic vector potential, $\mathbf{A}$ which is determined from the following Ampere's law:

$$
\nabla^{2} \mathbf{A}=-\mu_{0} \mathbf{j}
$$

where, $\mu_{0}$ is the magnetic permeability of free space.

Figure 1 shows a schematic diagram of the segmented arc heater composed of anode, constrictor, cathode, and Laval nozzle for the supersonic flow. In this work, thermal plasma characteristics were simulated from the anode end to the supersonic throat where the Mach

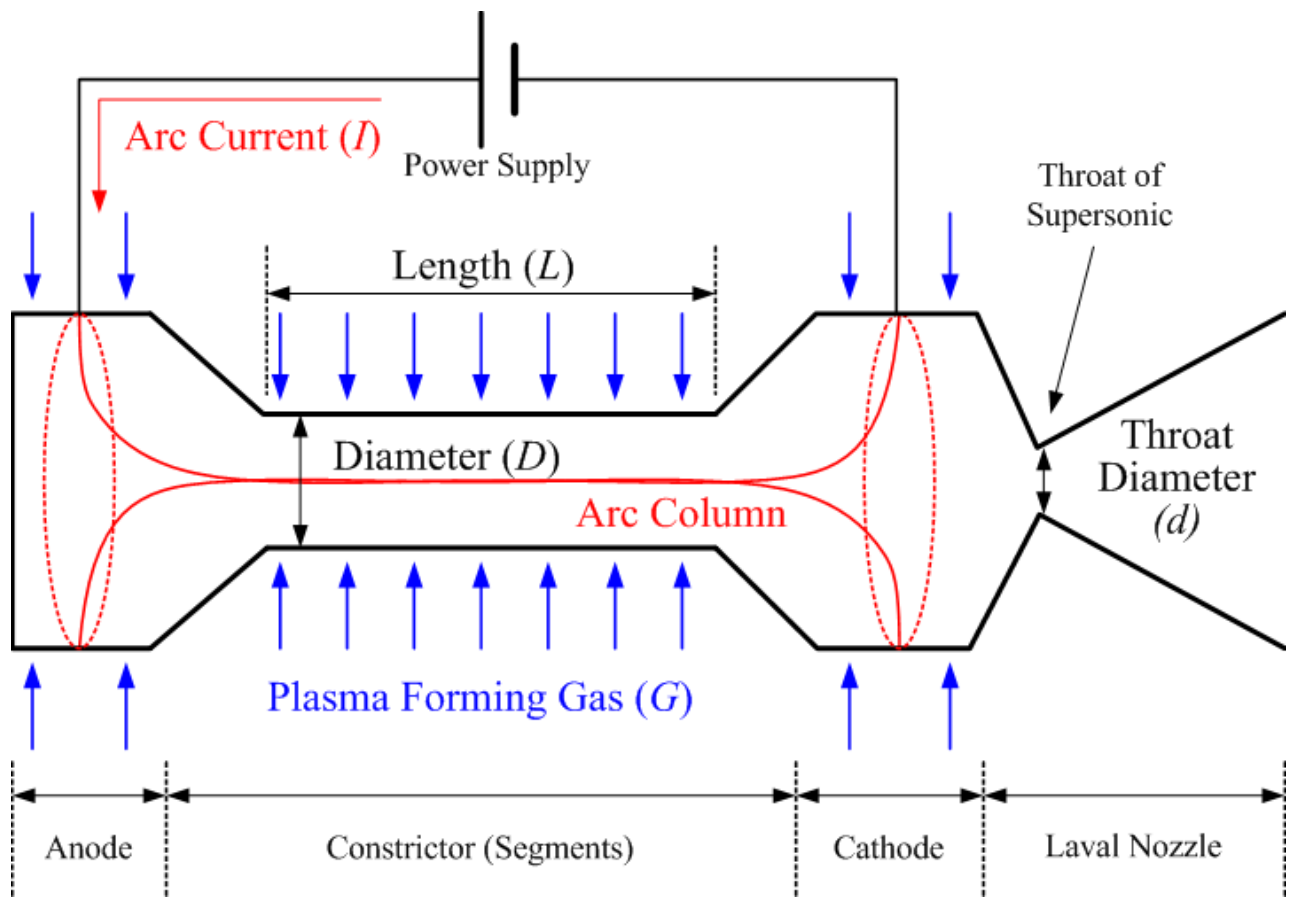

Fig. 1 Schematic diagram of the segmented arc heater with design and operation variables 
number reaches at 1 . A proper diameter of the supersonic throat $(d)$ was analyzed from the numerical simulation, and the diameters of Laval nozzle exit according to the Mach numbers were calculated from the following supersonic relationship between the cross sectional areas of the Laval nozzle and the Mach number:

$$
\frac{A}{A^{*}}=\frac{1}{M}\left[\frac{2}{\gamma+1}\left(1+\frac{\gamma-1}{2} M^{2}\right)\right]^{\frac{\gamma+1}{2(\gamma-1)}}
$$

where, $A, A^{*}, M$, and $\gamma$ are area at the Laval nozzle exit, area at the supersonic throat, Mach number, and isentropic exponent which was analytically calculated in Ref. (13).

The plasma forming gas of air in room temperature is supplied to torch through the gaps with $1 \mathrm{~mm}$ placed between each segments. Both electrode of cathode and anode are divided into three parts in the axial direction, accordingly they have each two air injection ports as shown in Fig. 1. On the other hands, the constrictor part has different numbers of air injection ports according to its length, because it has the gaps in every $15 \mathrm{~mm}$ in the axial direction. Moreover, there are two additional air injection ports between the constrictor and both of electrodes. In the present work, the same pressure of the injected air was assumed. Therefore, the total air flow rate was distributed to all injection ports according to the diameter at the axial position of air introduction region due to the same gap size of $1 \mathrm{~mm}$. Although all parts of the torch are cooled with water, they are exposed to severe heat and radiation transfer. Therefore, a fixed temperature of $1,000 \mathrm{~K}$ is use as a wall boundary condition which has shown a good agreement with experimentally measured thermal efficiency of the torch in the previous numerical and experimental work ${ }^{(6,9)}$. Although the electromagnetic properties such as electric potential and magnetic fields are calculated in the code as mentioned in Eq. (1) and Eq. (2), the initial electric conductivity is required, because non-conductive cold air is used. For this reason, the initial temperature was set as $1,000 \mathrm{~K}$ to give a small scale of the electric conductivity for a stable conservation of the simulation at the initiatory stage.

In the present work, effects of the operation variables were analyzed in the ranges of 300 $\sim 500$ A for the arc current $(I)$ and $6 \mathrm{~g} / \mathrm{s} \sim 14 \mathrm{~g} / \mathrm{s}$ for the plasma gas flow rate of air $(G)$, respectively. Along with the operating conditions, effects of the design variables on the thermal plasma characteristics were also investigated. Length $(L)$ and diameter $(D)$ of the constrictor were changed from $12 \mathrm{~mm}$ to $20 \mathrm{~mm}$ and from $105 \mathrm{~mm}$ to $315 \mathrm{~mm}$, respectively. Since the unit length of the segments pack was $105 \mathrm{~mm}$, the length of the constrictor was determined by the number of segments packs from 1 to 3 .

\section{Results and Discussion}

In the numerical results according to various design and operation conditions, thermal efficiency of the segmented arc heater with $400 \mathrm{~kW}$ level was around $60 \%$. Therefore, the flow rate of plasma forming gas has to be lower than $12 \mathrm{~g} / \mathrm{s}$, in order to achieve a high enthalpy over $20 \mathrm{MJ} / \mathrm{kg}$ at the torch exit. Although a low gas flow rate had an effect to increase the plasma enthalpy, a steep temperature gradient in the radial direction and large heat flux into the inner wall of the segments was expected as shown in Fig. 2. Since the plasma forming gas of air is injected through the gaps between each segment, thermal plasma in high temperature is cooled by the injected air and a wave like temperature distributions are shown near the wall region. In these temperature distributions, reduced heat damage on the segments is expected in a relatively higher gas flow rate due to a cooling effect of air. Therefore, a fixed gas flow rate of $10 \mathrm{~g} / \mathrm{s}$ was considered in the following work. 


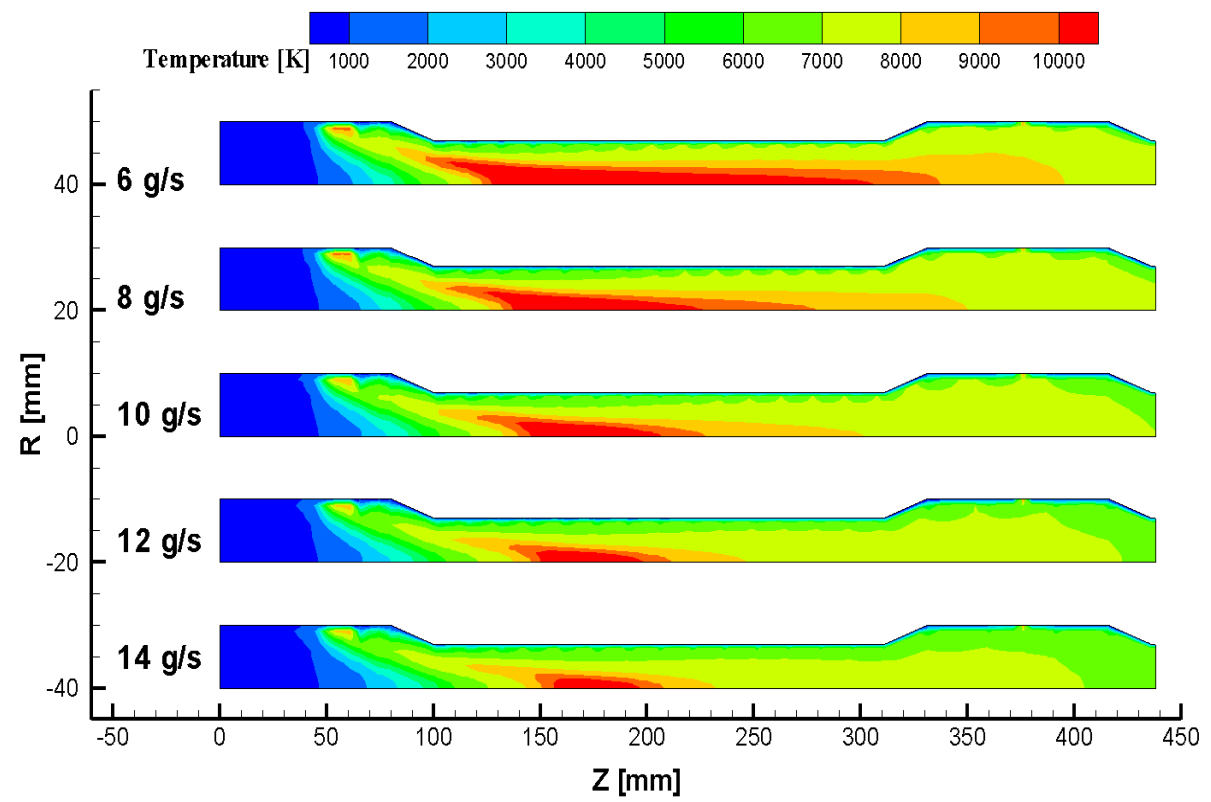

Fig. 2 Temperature distributions according to air flow rate $(G)$ at fixed other conditions of $I=400 \mathrm{~A}, D=14 \mathrm{~mm}, L=210 \mathrm{~mm}$, and $d=14 \mathrm{~mm}$
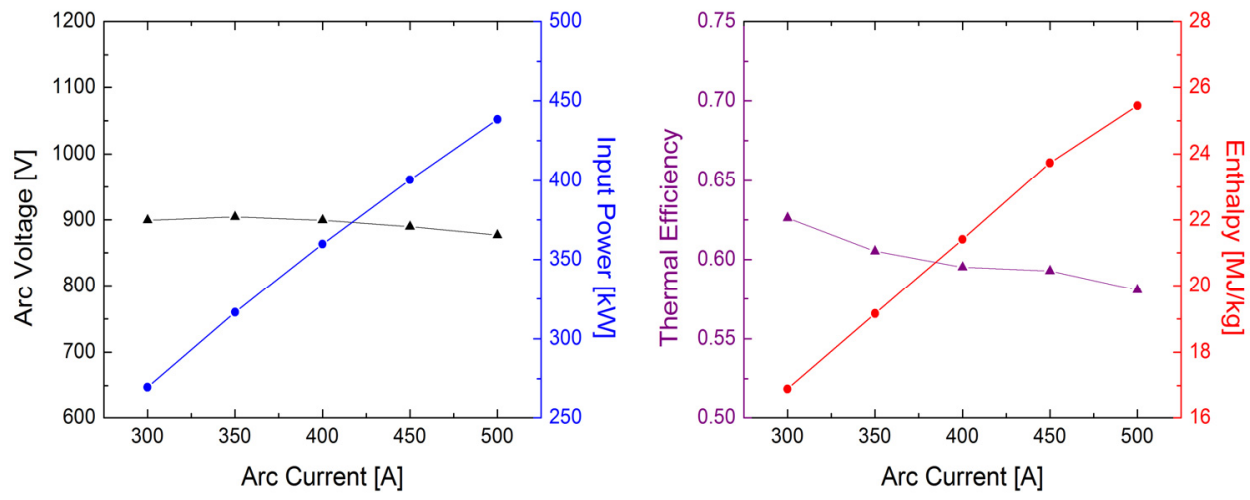

Fig. 3 Segmented arc heater performance according to the arc current from 300 A to $500 \mathrm{~A}$ at fixed other conditions of $G=10 \mathrm{~g} / \mathrm{s}, D=14 \mathrm{~mm}, L=210 \mathrm{~mm}$, and $d=14 \mathrm{~mm}$

Input power was enhanced with arc current increase as shown in Fig. 3 due to a hardly changed arc voltage at fixed air flow rate and constrictor geometry. Although a high arc current cause a fast erosion rate of electrodes, the segmented arc heater have to operate over 400 A to achieve over $20 \mathrm{MJ} / \mathrm{kg}$ at fixed air flow rate, constrictor diameter, constrictor length, an torch exit diameter of $10 \mathrm{~g} / \mathrm{s}, 14 \mathrm{~mm}, 210 \mathrm{~mm}$, and $14 \mathrm{~mm}$, respectively. In this way of numerical analysis on the torch performance, the high enthalpy condition was founded in various operating and design conditions.

As design variables, effects of diameter and length of constrictor on the torch performance were also analyzed to find out the relationship between design condition and thermal plasma characteristics. Input power and plasma enthalpy were proportional to constrictor length and inversely proportional to constrictor diameter. It is because that the arc voltage is directly affected by its length, and it is determined by constrictor length in the segmented arc heater. On the other hand, a small size diameter of the constrictor compresses the arc channel more effectively with cold plasma forming gas which is injected in the radial direction. For this reason the electric resistivity and the arc voltage are increased in 


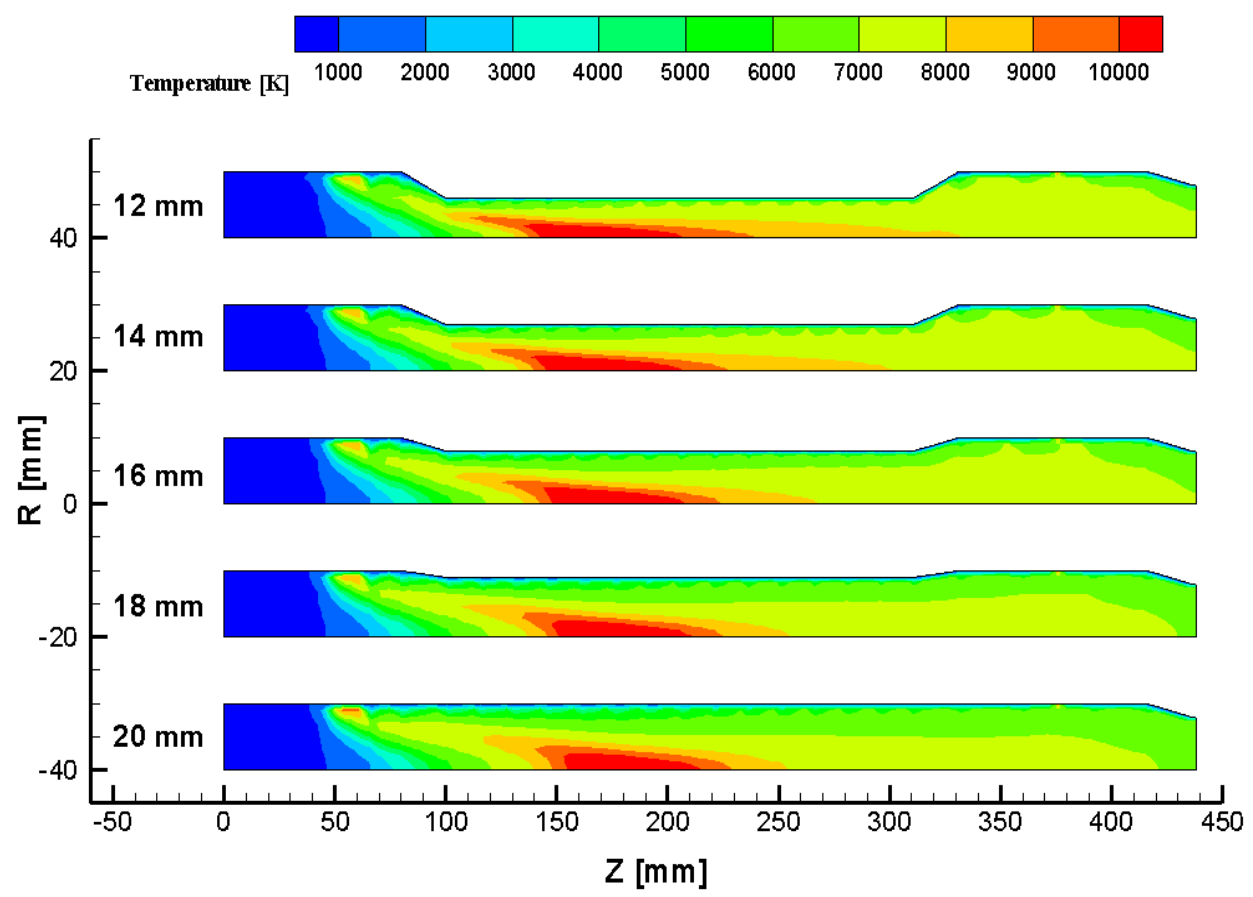

Fig. 4 Temperature distributions according to the constrictor diameter $(D)$ at fixed other conditions of $L=210 \mathrm{~mm}, I=400 \mathrm{~A}, G=10 \mathrm{~g} / \mathrm{s}$, and $d=16 \mathrm{~mm}$

the small constrictor diameter case. As shown in Fig. 4, a small diameter of the constrictor enhances Joule heating and temperature field by compressing the arc column. Since the shortest constrictor length with 1 pack of segments could not achieve the target input power of $400 \mathrm{~kW}, 210 \mathrm{~mm}$ and $315 \mathrm{~mm}$ were considered as constrictor length.

In order to achieve $400 \mathrm{~kW}$ and $20 \mathrm{MJ} / \mathrm{kg}$ with the plasma gas flow rate of $10 \mathrm{~g} / \mathrm{s}, 3$ kinds of conditions were suggested according to the arc current and the constrictor geometry as listed in the Table 1 . The torch exit diameter does not have a significant effects on the torch performance such as input power and enthalpy at the fixed other conditions. In a larger constrictor diameter case at the fixed constrictor length of $210 \mathrm{~mm}$, higher arc current is required than the case of smaller diameter to generate a similar input power level due to a weaker arc constriction and lower arc voltage. However, the larger diameter produces more enhanced enthalpy at the torch exit than the smaller diameter, due to a reduced heat loss into the segments inner surface. Since a longer constrictor increase the arc voltage, the long constriction length of $315 \mathrm{~mm}$ has the largest constrictor diameter to produce a similar input power level about $400 \mathrm{~kW}$.

In the selected conditions, radial profiles of Mach number, temperature, and pressure at the torch exit are compared in Figs. 5 7. Regardless of arc current and constrictor geometry, radial profiles of Mach number of the thermal plasma jet at the torch exit are around

Table 1 Selected constrictor geometry and arc current conditions at fixed air flow rate of $10 \mathrm{~g} / \mathrm{s}$ for $400 \mathrm{~kW}$ level segmented arc heater over $20 \mathrm{MJ} / \mathrm{kg}$ at torch exit

\begin{tabular}{|c|c|c||c|c|}
\hline $\begin{array}{c}L \\
(\mathrm{~mm})\end{array}$ & $\begin{array}{c}D \\
(\mathrm{~mm})\end{array}$ & $\begin{array}{c}I \\
(\mathrm{~A})\end{array}$ & $\begin{array}{c}\text { Input Power } \\
(\mathrm{kW})\end{array}$ & $\begin{array}{c}\text { Enthalpy at Torch Exit } \\
(\mathrm{MJ} / \mathrm{kg})\end{array}$ \\
\hline 210 & 12 & 400 & 416.42 & 22.01 \\
\hline 210 & 14 & 450 & 400.35 & 23.73 \\
\hline 315 & 16 & 400 & 391.20 & 22.53 \\
\hline
\end{tabular}




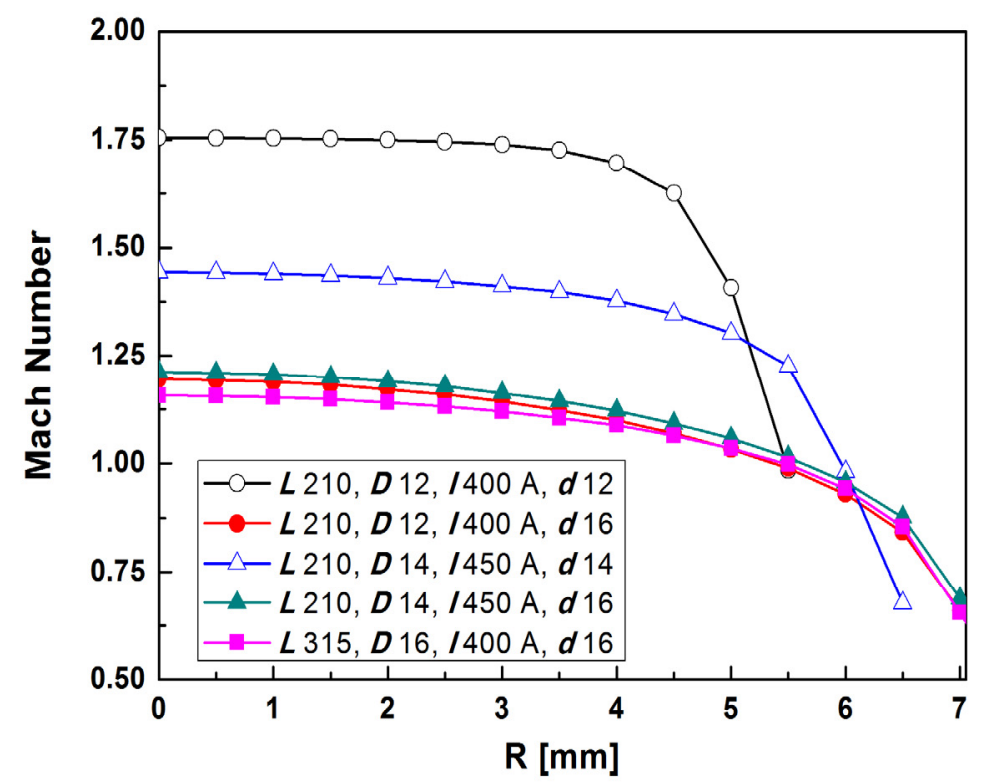

Fig. 5 Radial profiles of Mach number at the torch exit in the selected conditions with different diameters at the supersonic throat

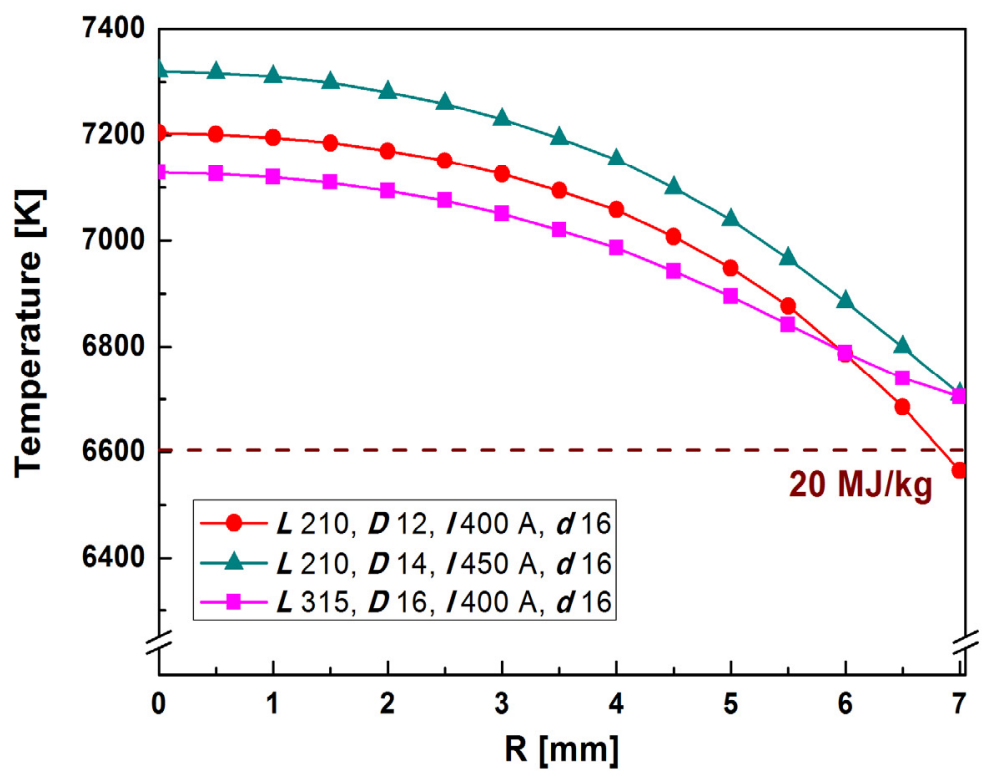

Fig. 6 Radial profiles of temperature at the torch exit in the selected conditions with fixed diameter of $16 \mathrm{~mm}$ at the supersonic throat

around 1 when the diameter of the supersonic throat $(d)$ was fixed at $16 \mathrm{~mm}$ as shown in Fig. 5. Gas enthalpy is determined by its temperature under LTE condition like as thermal plasma. In the case of air, $20 \mathrm{MJ} / \mathrm{kg}$ is relevant to $6,600 \mathrm{~K}^{(12,14)}$, and Fig. 6 shows that air temperature profiles at the supersonic throat surpass the desired value. The maximum internal pressure does not exceed 4 bar in the suggested conditions as shown in Fig. 7. Among the suggested conditions, the longest constrictor length produces most uniform temperature profile at the supersonic throat with the lowest pressure. Therefore, a stable operation of the segmented arc heater with a uniform heat load on the surface of the thermal protection system is expected in the longest constrictor length of $315 \mathrm{~mm}$ with the 


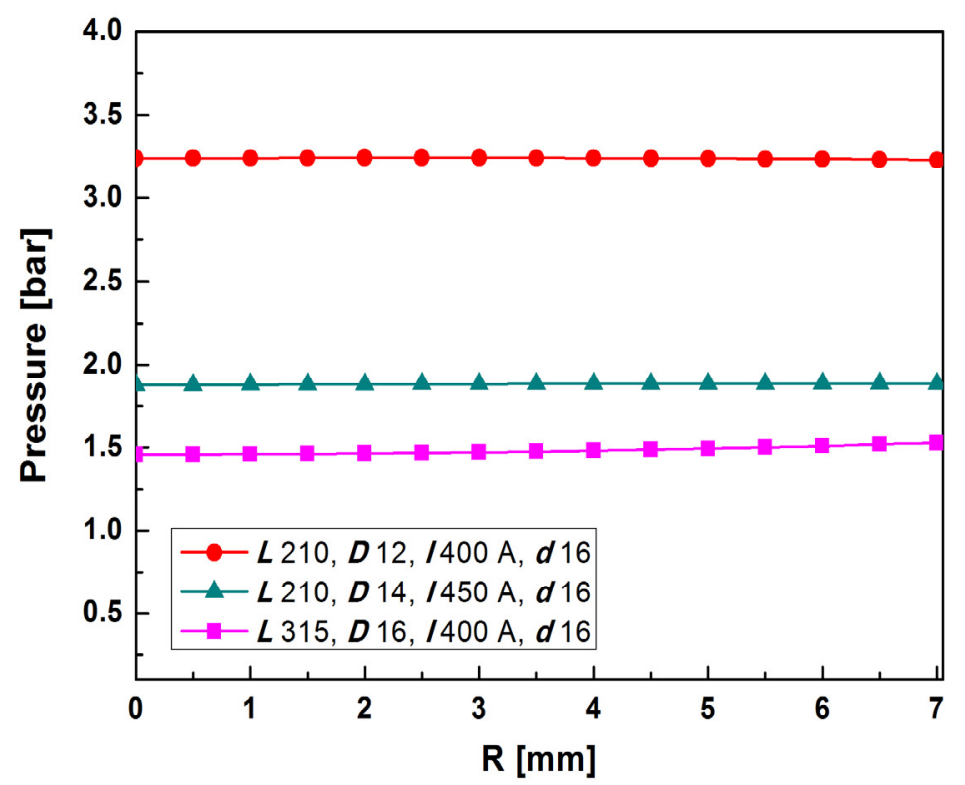

Fig. 7 Radial profiles of pressure at the torch exit in the selected conditions with fixed diameter of $16 \mathrm{~mm}$ at the supersonic throat

supersonic throat diameter of $16 \mathrm{~mm}$. In this condition of $16 \mathrm{~mm}$ at the supersonic throat, the exit diameters of the Laval nozzle were calculated as $55.5 \mathrm{~mm}$ and $82.4 \mathrm{~mm}$ by using Eq. (3) to produce the supersonic thermal plasma jet with Mach 2 and 3, respectively.

\section{Conclusion}

The characteristics of thermal plasma jet in the segmented arc heater were successfully analyzed by using the self-developed MHD computational code. In order to achieve the target power and enthalpy with an excellent property of the thermal plasma jet for a TPS test, it is required that the relatively long length of $315 \mathrm{~mm}$ and the large diameter of $16 \mathrm{~mm}$ for the constrictor as design variables. And for the operation variables, the arc current of 400 A was predicted at the fixed plasma gas flow rate of $10 \mathrm{~g} / \mathrm{s}$ in the optimal design condition of the segmented arc heater with $400 \mathrm{~kW}$ level.

\section{Acknowledgement}

This work was supported by Basic Science Research Program through the National Research Foundation of Korea funded by the Ministry of Education, Science and Technology (MEST) under the Project No. NRF-2010-0001829.

\section{References}

(1) Terrazas-Salinas, I. and Cornelison, C., Test Planning Guide for ASF Facilities, (1999), pp. 16-19, Thermophysics Facilities Branch Space Technology Division of NASA Ames Research Center.

(2) Purpura, C., Filippis, F. D., Graps, E., Trifoni, E., and Savino, R., The GHIBLI plasma wind tunnel: Description of the new CIRA-PWT facility, Acta Astronautica, Vol. 61 (2007), pp. 331-340.

(3) Hirakawa, M., Abe, K., Nishida, M., Takeishi, K., and Matsuura, M., Application of a 
$20 \mathrm{~kW}$ Arc-Heated Wind Tunnel to Evaluation Tests of Wall Catalysis, Transactions of the Japan Society for Aeronautical and Space Sciences, Vol. 45, No. 150 (2003), pp. 217-223.

(4) Hur, M. and Hong, S. H., Comparative analysis of turbulent effects on thermal plasma characteristics inside the plasma torches with rod- and well-type cathodes, Journal of Physics D: Applied Physics, Vol. 35 (2002), pp. 1946-1954.

(5) Park, J. M., Kim, K. S., Hwang, T. H., and Hong, S. H., Three-Dimensional Modeling of Arc Root Rotation by External Magnetic Field in Nontransferred Thermal Plasma Torches, IEEE Transactions on Plasma Science, Vol. 32, No. 2 (2004), pp. 479-487.

(6) Choi, S., Lee, H. S., Kim, S., Hong, S. H., and Park, D. -W., Thermal Plasma Analysis for the Pyrolysis of PFCs on a Large Scale, Journal of the Korean Physical Society, Vol. 55, No. 5 (2009), pp. 1819-1824.

(7) Kim, K. S., Park, J. M., Choi, S., Kim, J., and Hong, S. H., Comparative study of two- and three-dimensional modeling on arc discharge phenomena inside a thermal plasma torch with hollow electrodes, Physics of Plasmas, Vol. 15 (2008), p. 023501.

(8) Choi, S., Hwang, T. H., Seo, J. H., Kim, D. U., and Hong, S. H., Effects of Anode Nozzle Geometry on Ambient Air Entrainment Into Thermal Plasma Jets Generated by Nontransferred Plasma Torch, IEEE Transactions on Plasma Science, Vol. 32, No. 2 (2004), pp. 473-478.

(9) Kim, K. S., Park, J. M., Choi, S., Kim, J., and Hong, S. H., Enthalpy probe measurements and three-dimensional modelling on air plasma jets generated by a non-transferred plasma torch with hollow electrodes, Journal of Physics D: Applied Physics, Vol. 41 (2008), p. 065201.

(10) Gleizes, A., Gonzalez, J. J., and Freton, P., Thermal plasma modeling, Journal of Physics D: Applied Physics, Vol. 38 (2005), pp. R153-R183.

(11) Li, H. -P., Pfender, E., and Chen, X., Application of Steenbeck's minimum principle for three-dimensional modelling of DC arc plasma torches, Journal of Physics D: Applied Physics, Vol. 36 (2003), pp. 10846-1096.

(12) Murphy, A. B., Transport Coefficients of Air, Argon-air, Nitrogen-Air, and Oxygen-Air Plasmas, Plasma Chemistry and Plasma Processing, Vol. 15, No. 2 (1995), pp. 279-306.

(13) Matsuzaki, R, Analytical Expressions for Specific Heats and Isentropic Exponent of High Temperature Gases. II. Air, Japanese Journal of Applied Physics, Vol. 21, No. 7 (1982), pp. 1009-1013.

(14) Boulos, M. I., Fauchais, P., and Pfender E., Thermal Plasmas: Fundamentals and Applications, Vol. 1 (1994), p. 414, Plenum Press. 